Annuska Zolyomi and Joseph T. Tennis. 2017. Autism Prism: A domain Analysis Paper Examining Neurodiversity. NASKO, Vol. 6. pp. 139-172.

Annuska Zolyomi

Joseph T. Tennis

University of Washington Information School

\title{
Autism Prism: A Domain Analysis Examining Neurodiversity
}

\begin{abstract}
Autism is a complex neurological phenomenon that affects our society on individual, community, and cultural levels. There is an ongoing dialog between the medical, scientific and autism communities that critiques and molds the meaning of autism. The prevailing social model perspective, the neurodiversity paradigm, views autism as a natural variation in human neurology. Towards the goal of crystallizing the various facets of autism, this paper conducts a domain analysis of neurodiversity. Through this analysis, we explore the dynamics between diagnosis, identity, power, and inclusion.
\end{abstract}

\section{Introduction}

"My diagnosis was officially Asperger's, although I've been informed that people stopped using that for whatever reasons I don't understand."

(Participant 2 in research on the experiences of autistic college students, March 2017)

The public's awareness of autism is on the rise, influenced by voices of autistic people, advocates, government health organizations, private organizations, politicians, and celebrities ${ }^{1}$. These often-conflicting voices complicate and, at times, obfuscate, the realities of the lived experiences of autism (Davidson and Orsini 2013). Autism is a phenomenon that motivates intense engagement in the psychological, neurological, biomedical, and genetic fields. Autism has been the target of controversy with biased, unfounded claims about its cause, even when these claims have been repeatedly proven as false. Amidst evolving knowledge about autism, individuals with autism and their families continually aspire to voice their needs, concerns, and perspectives (Kenny et al. 2015). A neurodiversity paradigm is emerging that embraces differences due to natural diversity in human neurology.

This work uses a classification strategy, domain analysis, to examine the terms used to construct the concept of neurodiversity. Similar to other disabilities, autism is often conceptualized from two primary models: a medical model and a social model. This paper argues that the multi-faceted experiences of autistic people are not adequately represented by solely either model. Rather, each model can provide value when it gives us a deeper understanding of the nature of autism, within the context of a person's biological, social, and personal stance. We explore the tensions between these models, and in doing so, we seek to illuminate issues of identity, power, and inclusion. We suggest implications to the design of

\footnotetext{
${ }^{1}$ We use identity-first ("autistic people") and person-first language ("people with autism") interchangeably to reflect the diversity of preferences within the neurodiversity community (Kenny et al. 2015) and to recognize that terminology choices are context-sensitive.
} 
Annuska Zolyomi and Joseph T. Tennis. 2017. Autism Prism: A domain Analysis Paper Examining Neurodiversity. NASKO, Vol. 6. pp. 139-172.

information systems that embed neurodiversity concepts and that aim to be used by neurodiverse communities. We offer a comprehensive thesaurus to the research community, information system designers, and neurodiverse individuals and their Circle of Care in the hopes that it provides a useful vocabulary and starting point for their explorations.

\section{Related Work}

\section{Disability Models}

A common framework for examining a disability is to establish its medical and social models. The medical model is concerned with the clinical pathology of a disease with an emphasis on the cause, origin, and nature of the disease. Many disability studies scholars and selfadvocates view the medical model as presenting disability as "stemming from the functional limitations or psychological losses which are assumed to arise from disability" (Oliver 1990 p.2). They are opposed to a disability being medicalized to the extent that the goal becomes medical intervention and control over conditions that deviate from the norm (S. Linton 1998). The medical model is alternatively referred to as the individual model since "it locates the 'problem' of disability within the individual" (Oliver 1990 p.2).

In contrast, the social model considers disability to be a social condition because society presents barriers and fails "to provide appropriate services and adequately ensure the needs of disabled people are fully taken into account in its social organization" (Oliver 1990 p.2). This model makes a clear distinction between disability and illness, which can appropriately require medical treatment. Another critical distinction is between impairment and disability. Impairment is an individual's functional limitations; whereas, disability is a loss of opportunities as a byproduct of social and economic structures (Anastasiou and Kauffman 2013).

\section{Analysis of Autism Classification Systems}

Disability scholars and academic researchers have investigated autism-related classification systems and their impact on people's lived experiences (S. Linton 1998; Volkmar and McPartland 2014; Giles 2014). Our work is distinct in two ways: (1) it examines the emerging phenomenon of neurodiversity, and (2) it is situated in knowledge organization theory and practices. Our work follows the research front in knowledge organization that is concerned with understanding particular domains (Hjørland 1998; Campbell 2012), understanding the power of naming (Olson 2001), and surfacing previously unconcerned conceptual structures (Fox 2016). Kwasnik and Flaherty (2010) conducted an autism domain analysis to differentiate between "professional" (based on scientific research) as opposed to "naïve" classification schemes. Through an analysis of the MeSH (Medical Subject Headings) and WebMD schema representing autism, they found that MeSH presented as a more authoritarian voice; whereas, WebMD was more up-to-date on vocabulary. To the authors' knowledge, our domain analysis is the first holistic examination of neurodiversity discourse arising from the medical and social models. What follows is our analysis of the relevant documents and media we used to create a descriptive domain analysis. 
Annuska Zolyomi and Joseph T. Tennis. 2017. Autism Prism: A domain Analysis Paper Examining Neurodiversity. NASKO, Vol. 6. pp. 139-172.

\section{Method}

To begin our domain analysis, we identified the primary actors in the discourse on autism. One of our primary sources was The Diagnostic and Statistical Manual of Mental Disorders (DSM), $5^{\text {th }}$ edition (American Psychiatric Association 2013) since it dictates the criteria for medical diagnoses. We cross-referenced the DSM with the World Health Organization's International Statistical Classification of Diseases and Related Health Problems (ICD-10) (World Health Organization 2010). We then conducted an academic literature review to identify recent research studying families with autistic children and autistic individuals. To supplement this scholarly knowledge, we drew from autism self-advocates' books (Grandin and Panek 2014), organizations ("Autism Network International" 2017, "Autistic Self Advocacy Network | Nothing About Us Without Us” 2017, “The National Autistic People's Organisation" 2017), and blogs (Walker 2014). A few sources reflect both a social and medical model ("Autism Speaks" 2017, "Spectrums Magazine from Autism Empowerment" 2017). For example, Autism Speak hosts a glossary with medical model terms, yet it is an organization founded by grandparents of a child with autism. We also reference dictionaries and encyclopedias ("Double-Tongued Dictionary Index | A Way with Words" 2016, "Oxford English Dictionary Online" 2016).

Towards substantiating the credibility of the online sources, we ensured that (1) they had been referenced by at least one other online source, and (2) the author self-identified as autistic. We acknowledge that online sources do not undergo a rigorous process like peerreviewed academic articles. By selecting specific medical and social sources, and excluding others, we are inherently choosing which voices to surface. For instance, we chose to focus on the DSM-V as the key medical text and did not extend our search into medical subfields, such as MeSH for biomedical literature. In the medical sources, we searched for content using the search terms: "neurodiversity," "autism," and "autism spectrum disorder." In the social sources, we found glossaries and posts by searching using those same search terms. We gathered, organized, and compared terms and definitions used across sources. Our criteria for selecting the terms for our taxonomy were that they were (1) named by more than one source as a key element of the autism experience, and (2) they were useful in bounding the breadth and depth of the autism experience.

This domain analysis is a snapshot of contemporary vocabulary, issues, and perspectives. While we have attempted to capture the key taxonomy, we recognize that we cannot be completely thorough in our analysis and we regret any key omissions or mischaracterizations we may make. We also recognize that we bring our own biases into this work as we engage with the sources and make editorial choices. We offer this analysis as a contribution to the ongoing, rich dialog that will help evolve our understanding of neurodiversity.

\section{Taxonomy}

We present a taxonomy with the root term of neurodiversity $(0.0)$ that reflects perspectives of the medical and social communities. Neurodiversity was chosen as the root term because, from a community perspective, neurodiversity embraces the naturally occurring diversity of human biology. Whereas, from a medical model, the broader term for autism stemmed from mental disabilities. As shown in Figure 1, we chose to branch 
Annuska Zolyomi and Joseph T. Tennis. 2017. Autism Prism: A domain Analysis Paper Examining Neurodiversity. NASKO, Vol. 6. pp. 139-172.

up to neurodiversity instead because it situates autism among other neurodiverse conditions that are experienced as intrinsic to a person's sense of self (Walker 2014). The following sections show the relationships between the terms. All the terms are defined in the Neurodiversity Thesaurus Appendix.

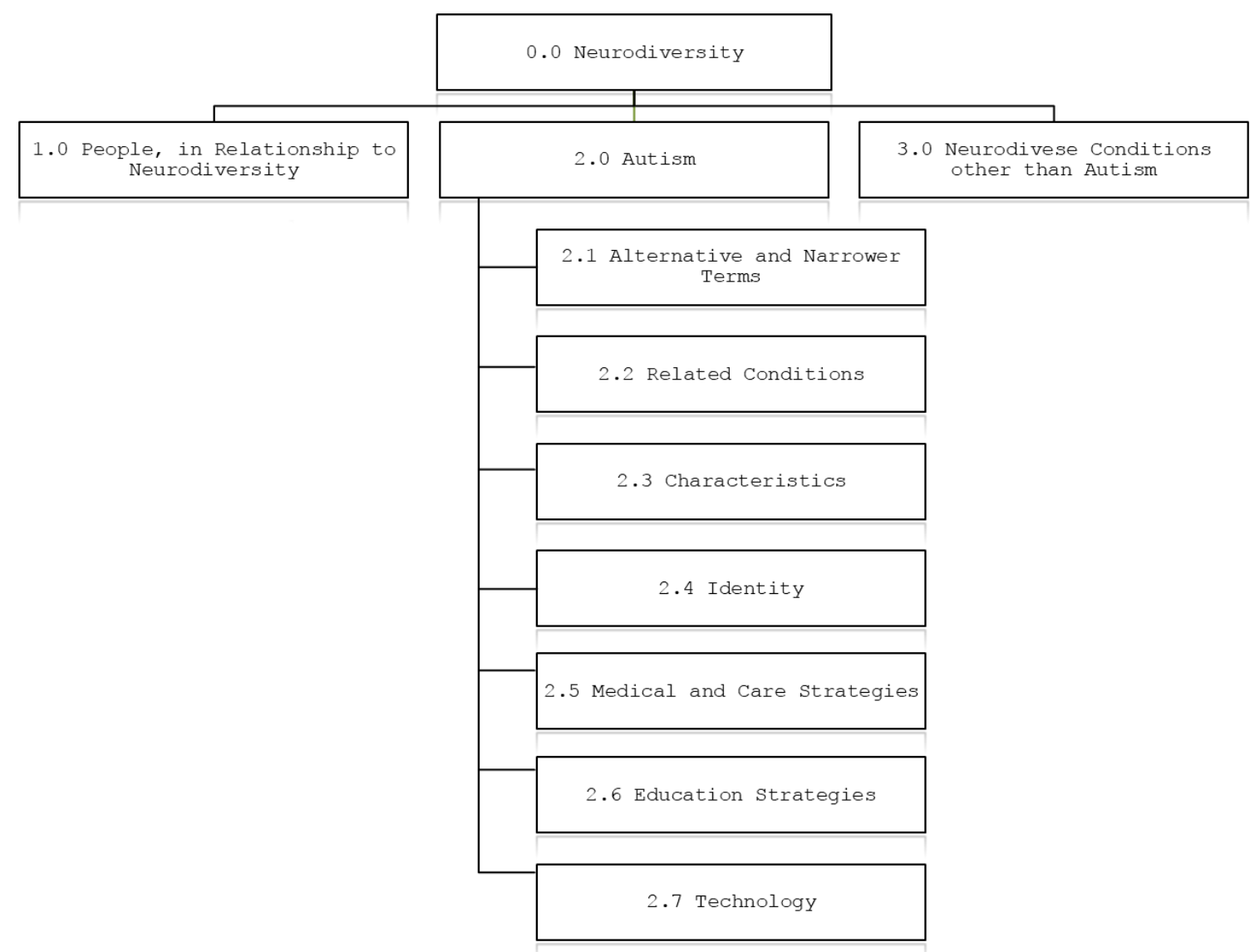

Figure 1: Top level categories of our Neurodiversity taxonomy.

\subsection{Neurodiversity}

The root term of our taxonomy, neurodiversity $(0.0)$, emphasizes the diversity of human neurology. This term is attributed to sociologist and autism self-advocate, Judy Singer (Singer 1999). She approaches her work from a feminist, post-modern theoretical stance. She argues that "we need to transcend the construction of binary oppositions such as "Medical 
Annuska Zolyomi and Joseph T. Tennis. 2017. Autism Prism: A domain Analysis Paper Examining Neurodiversity. NASKO, Vol. 6. pp. 139-172.

Model vs Social Model" ((Singer 2016, Chapter "Social constructionism vs biological determinism"). Neurodiversity is an emerging synthesis that builds upon the models' positives attributes and espouses a generative, open stance of autistic life.

0.0 Neurodiversity: "The whole of human mental or psychological neurological structures or behaviors, seen as not necessarily problematic, but as alternate, acceptable forms of human biology" ("Double-Tongued Dictionary Index | A Way with Words" 2016). "Differently brained" (Armstrong 2011).

\subsection{People, in relationship to neurology}

The first component of the taxonomy describes individuals in terms of their neurology. Most these terms forefront neurology as the point of distinction, not deficit. One exception is the positioning of neurotypical (1.5) as opposed to neuro-atypical (1.4), which sustains the problematic juxtaposition of "normal" as opposed to "other." Another exception is neurodevelopmental disorders (1.8), whose reference to deficits is an inherent aspect of medical classification. The definitions for these and subsequent terms are in the Neurodiversity Thesaurus Appendix.

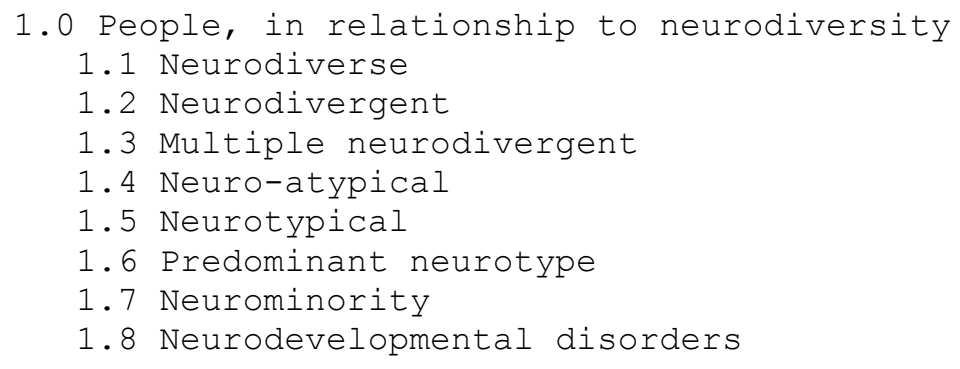

2.0 Autism

The next set of terms describe the spectrum of autism and alternative terms that were either used historically or that have been adopted by the community. Table 1 shows how the DSMIV and ICD-10 autism classifications map to the DSM-V classification.

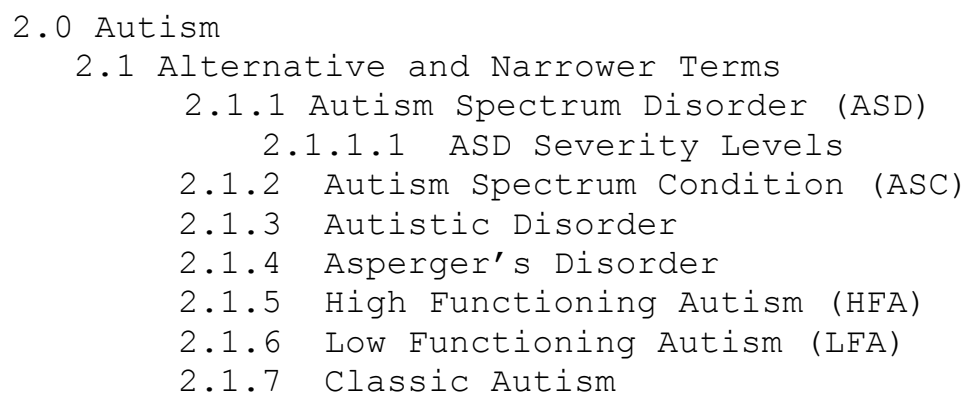


Annuska Zolyomi and Joseph T. Tennis. 2017. Autism Prism: A domain Analysis Paper Examining Neurodiversity. NASKO, Vol. 6. pp. 139-172.

\subsubsection{Pervasive Development Disorder - Not Otherwise Specified (PDD-NOS)}

\begin{tabular}{|c|c|c|}
\hline \multirow{2}{*}{$\begin{array}{l}\text { DSM-5 } \\
(2013-n o w)\end{array}$} & \multicolumn{2}{|c|}{ Pervasive Developmental Disorder } \\
\hline & $\begin{array}{l}\text { DSM-IV } \\
\text { DSM-IV-TR }(2000-2013)\end{array}$ & ICD-10 (1996-now) \\
\hline \multirow{5}{*}{$\begin{array}{l}299.00 \\
\text { Autism } \\
\text { Spectrum } \\
\text { Disorder } \\
(2.1 .1)\end{array}$} & 299.00 Autistic Disorder (2.1.3) & F84.0 Childhood Autism \\
\hline & $\begin{array}{l}\text { 299.80 Asperger's Disorder } \\
(2.1 .4)\end{array}$ & F84.5 Asperger Syndrome \\
\hline & \multirow{3}{*}{$\begin{array}{l}\text { 299.80 Pervasive Developmental } \\
\text { Disorder - not otherwise specified } \\
\text { (including Atypical Autism) - PDD- } \\
\text { NOS }(2.1 .8)\end{array}$} & F84.1 Atypical Autism \\
\hline & & $\begin{array}{l}\text { F84.8 Other pervasive } \\
\text { developmental disorders }\end{array}$ \\
\hline & & $\begin{array}{l}\text { F84.9 Pervasive developmental } \\
\text { disorders, unspecified }\end{array}$ \\
\hline & & $\begin{array}{l}\text { F84.4 Overactive disorder } \\
\text { associated with mental retardation } \\
\text { and stereotyped movements }\end{array}$ \\
\hline & 299.80 Rett's Disorder $(2.2 .4)$ & F84.2 Rett's Syndrome \\
\hline & $\begin{array}{l}\text { 299.10 Childhood Disintegrative } \\
\text { Disorder }(2.2 .5)\end{array}$ & $\begin{array}{l}\text { F84.3 Childhood Disintegrative } \\
\text { Disorder }\end{array}$ \\
\hline
\end{tabular}

Table 1: Mapping of Autism Spectrum Disorder classifications between DSM-V, DSM-IV and ICD-10. (Autism Aspergers Advocacy Australia 2017). Our neurodiversity taxonomy numbers are in parenthesis.

\subsection{Related Conditions}

This section lists some, not all, of the conditions that have a connection to autism. These relationships between conditions are of different forms, such as autism-adjacent (similar to), co-morbid (a second order diagnosis), or distinct from autism. Examples of the latter are Autism's relationships with Rett syndrome and Childhood Disintegrative Disorder. The DSM-IV offers a comparison of those two conditions as exclusion criteria for Autistic Disorder, stating that Autistic Disorder may be the diagnosis when the "disturbance is not better accounted for by Rett syndrome or childhood disintegrative disorder."

Our taxonomy is not exhaustive since comorbidity and genetic research are actively exploring the relationships of autism with conditions such as mood disorders, sleep disorders, epilepsy, and gastrointestinal dysfunction, and gender dysphoria) (Glidden et al. 2016; Mannion and Leader 2013).

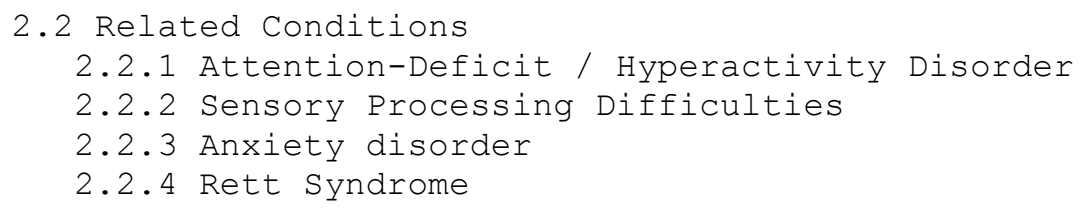


Annuska Zolyomi and Joseph T. Tennis. 2017. Autism Prism: A domain Analysis Paper Examining Neurodiversity. NASKO, Vol. 6. pp. 139-172.

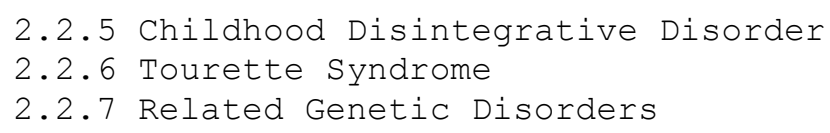

\subsection{Characteristics of Autism}

Autism is a collection of characteristics across social, communication and behavior dimensions. This section of the taxonomy highlights the complexity of autism, especially given that these characteristics interact and mingle, not acting in isolation. We also see that there are many ways these characteristics are named and the word choices of different communities.

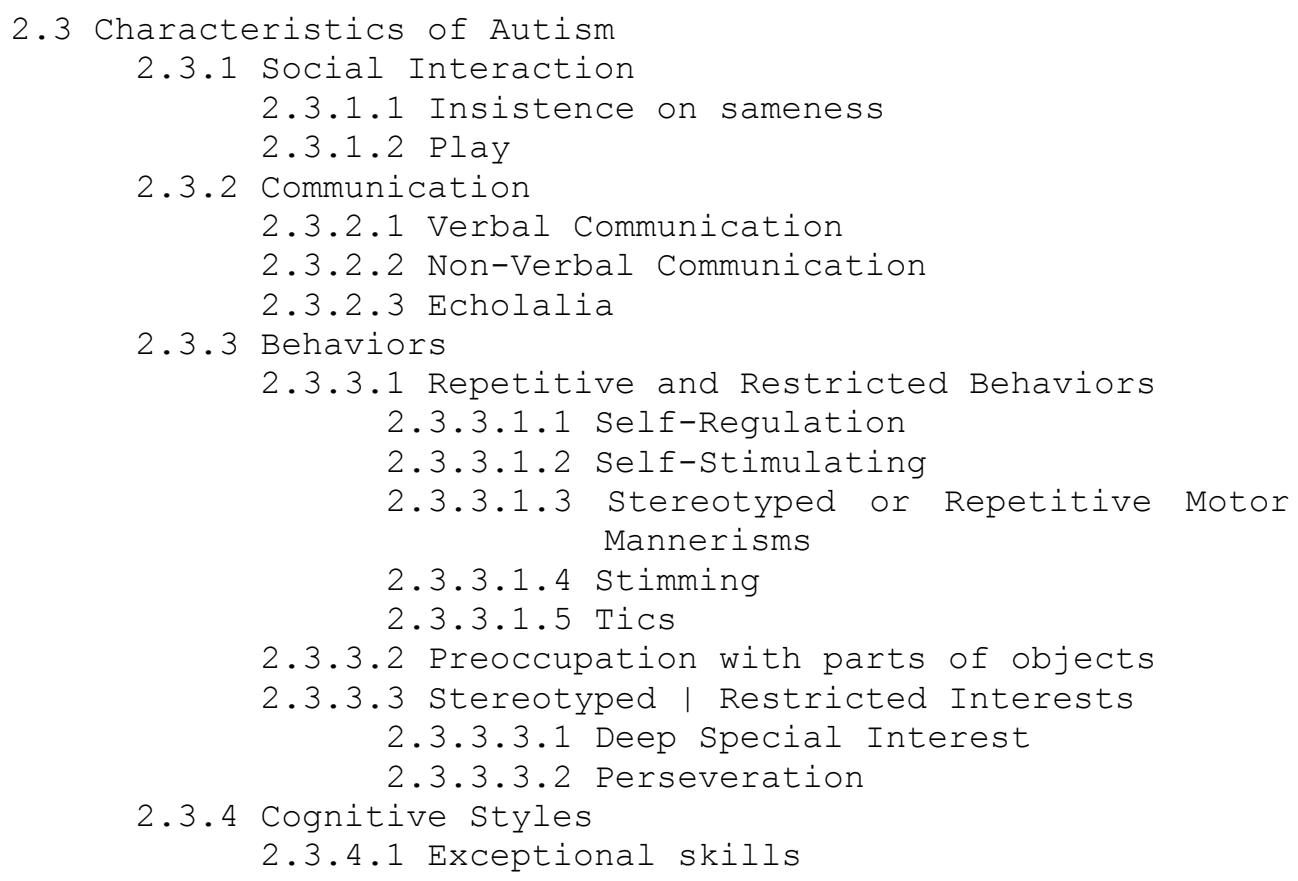

\subsection{Identity}

This section captures terms that point to a person's connection to autism. There are those who were diagnosed as a young child and those who wonder, as an adult, if they have autism. A neurodiversity diagnosis often creates access to mental health, education, and other services (Giles 2014). For unofficial diagnoses, an individual can take self-assessment tests online, such as the Autism Quotient for adolescents or adults. (Baron-Cohen et al. 2006; BaronCohen et al. 2005). The last set of Identity terms illuminate the social nature of autism by highlighting the stance and roles of people relating to autism. 
Annuska Zolyomi and Joseph T. Tennis. 2017. Autism Prism: A domain Analysis Paper Examining Neurodiversity. NASKO, Vol. 6. pp. 139-172.

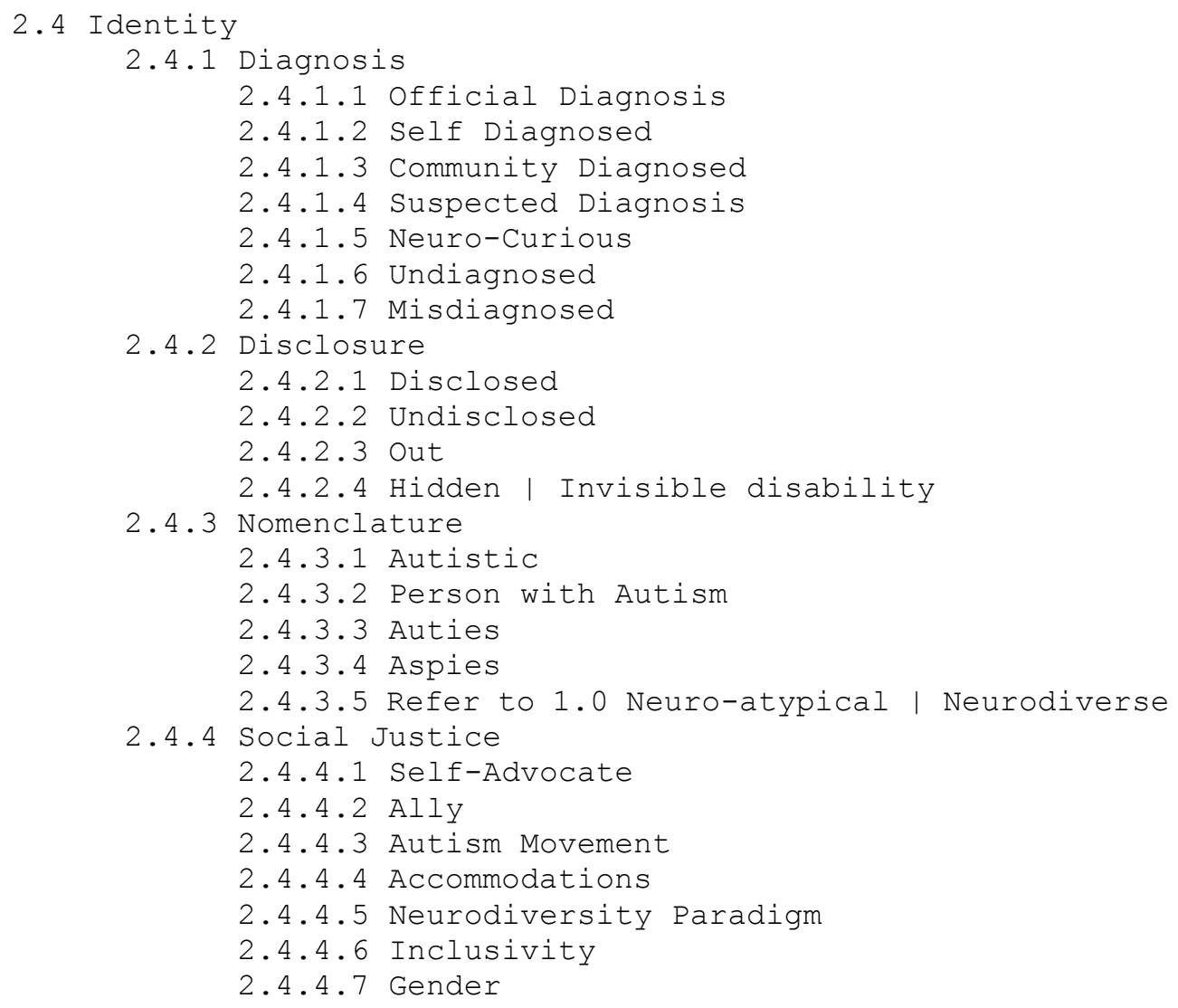

\subsection{Medical and Care Strategies}

The next collection of terms forefronts the medical model and strategies. The controversial terms of "Cause" and "Cure" are in direct opposition with the neurodiverse paradigm that considers neurodiversity as a difference to be celebrated, not suppressed or eliminated. As families and individuals explore their experiences and difficulties, they often seek therapeutic, social, and medical courses of action, as listed below. Note that this is not meant to be an exhaustive list of the strategies used and available.

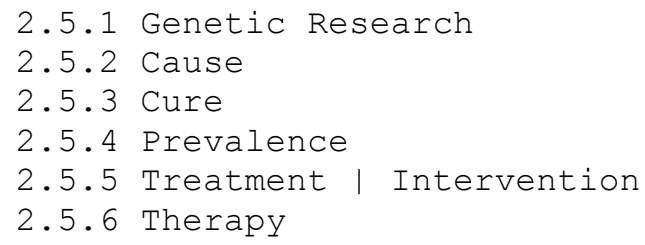


Annuska Zolyomi and Joseph T. Tennis. 2017. Autism Prism: A domain Analysis Paper Examining Neurodiversity. NASKO, Vol. 6. pp. 139-172.

\author{
2.5.6.1 Speech Therapy \\ 2.5.6.2 Occupational Therapy \\ 2.5.6.3 Physical Therapy \\ 2.5.6.4 Applied Behavior Analysis \\ 2.5.6.5 Social Skills Treatment \\ 2.5.7 Interdisciplinary health team \\ 2.5.8 Circle of Care \\ 2.5.9 Adaptive Behavior \\ 2.5.10 Non-traditional Strategies
}

\title{
2.6 Education Strategies
}

These terms reflect the U.S. model for educational supports for children with a diagnosis. By law, teaching practices must be based on evidence of effectiveness (Wong et al. 2014).

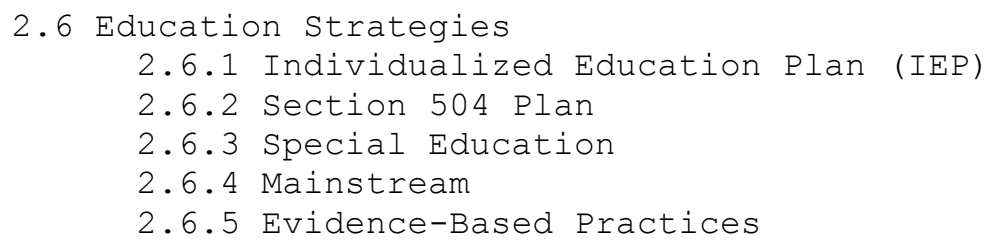

\subsection{Technology}

Technology can be an important aspect of education, intervention, and socialization for autistic people. The following high-level categorization is an entry point into the myriad of technologies in use (Kientz et al. 2013).

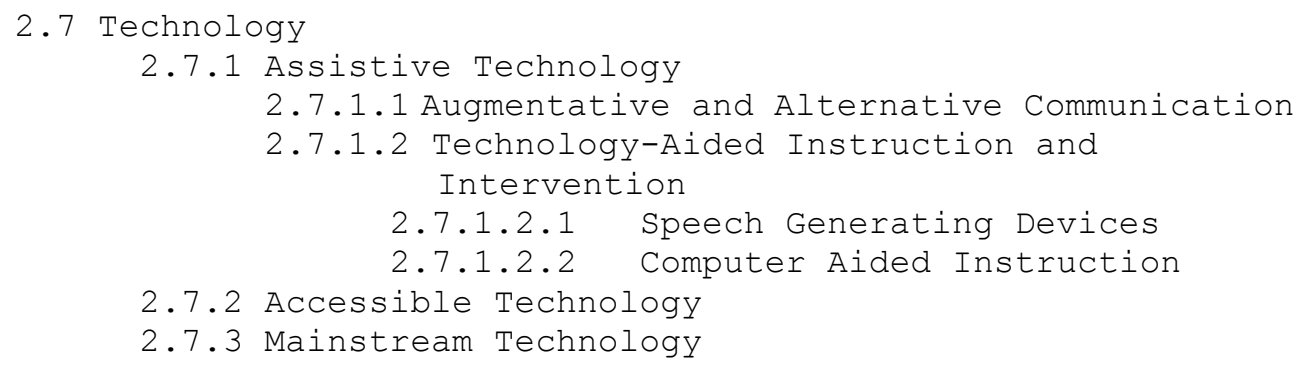

\subsection{Non-Autism Neurodiverse Conditions}

The next section of the taxonomy captures some of the conditions under the neurodiversity umbrella term. There is an open question as to what constitutes a neurodiversity condition. Our sources most commonly listed autism and ADHD as the example neurodiverse conditions. Since we are making editorial choices of which terms to list, but do not intend to exclude conditions, we have created a placeholder, 3.5, for other conditions that are due to 
Annuska Zolyomi and Joseph T. Tennis. 2017. Autism Prism: A domain Analysis Paper Examining Neurodiversity. NASKO, Vol. 6. pp. 139-172.

neurological differences. Some people with brain differences may or may not choose to identify as neurodiverse, so this categorization is an individual choice not a diagnosis.

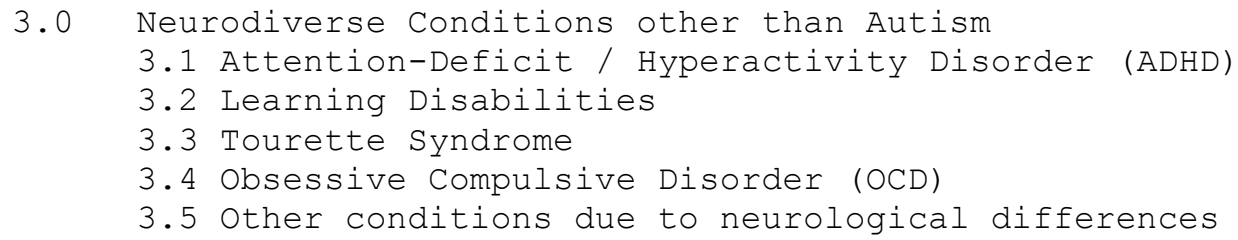

\section{Discussion}

This domain analysis highlights that autism is far from a static phenomenon. As the medical field discovers more about the genetic underpinnings and the biological impacts of autism, medical professionals are working to keep their diagnostic and treatment practices current. The autism community is evolving as well. The sheer size of the community is expanding due to the increased number of diagnosis, children being diagnosed earlier, more females being recognized as autistic, and adults self-diagnosing or being community diagnosed. The nature of the neurodiversity movement will continue to shift as self-advocates add their voices to the dialog. Based on this snapshot of the current taxonomy, our domain analysis reveals sources of power and nodes of tension. We posit that articulating and respecting an individual's identity is a mechanism for disentangling the complexities of the autism phenomenon. We conclude by offering implications to the design of information systems related to autism.

\section{Sources of Power}

In classification, power arises in the ability to name and be active in the discourse. In the case of neurodiversity, the power to name originates from those leading medical advances, but then is morphed by empowered community members. Drs. Kanner and Asperger encountered children with symptoms that did not fit any known conditions and created the diagnoses of Asperger and Autism (Silberman 2016; Donvan and Zucker 2016). As a term of endearment, Aspies (2.4.3.4) those with Asperger and their families take ownership over the diagnosis. Another example is how neurodevelopmental disabilities (1.8) was firmly rooted in the medical community, but then was altered to neurodiversity $(0.0)$ by Judy Singer, a sociology scholar, who is herself autistic and has a daughter on the autism spectrum. The term may have been isolated to an academic thesis if it had not been communicated to, and embraced by, the autistic community.

Even though these taxonomy movements appear to be contained within a medical or social model, it is a more nuanced dialog. Within each model are dissenting views and views that cross models. For instance, autistic people have individual preferences for disability-first or people-first language (Kenny et al. 2015). Although there is a prevailing preference for disability-first language, it is not one hundred percent representative of the community. Some autistic people embrace the concept of neurodiversity, while others do not. 
Annuska Zolyomi and Joseph T. Tennis. 2017. Autism Prism: A domain Analysis Paper Examining Neurodiversity. NASKO, Vol. 6. pp. 139-172.

These disagreements are not easily resolved, and perhaps, do not need to be resolved by choosing one solution. We can give the individual the power to claim the terms they prefer.

\section{Nodes of Tension}

Our taxonomy has multiple locations, or nodes, where there are opposing views. These nodes tend to occur where there are values and judgements embedded in the terminology. When describing human nature as one entity as opposed to another, as in the case of neurotypical (1.5) and neuro-atypical (1.4), we place one group of people as "the other." An equivalent term to neurotypical is predominant neurotype (1.6) which pivots on dominant versus minority. This is an attempt to create terminology that differentiates based on numbers, not as a value judgment. Someone who is a neurominority is part of a smaller group within the neurodiversity. This layered effect of a minority group within a minority group highlights the complexity of power and access to resources.

Another location of bias in terminology is the distinction of low and high functioning in the autism spectrum diagnosis. "Low" versus "high" is considered by some to be a false dichotomy since a person is neither high nor low functioning in all aspects of their life. Labeling someone as low functioning is a limiting judgment on someone's abilities and contributions. On the other hand, classifying someone as high functioning can be seen as erasing the real and consequential issues faced by all people on the spectrum (Kenny et al. 2015).

A major node of tension is the Medical and Care Strategies. There is a strong dichotomy between cure, cause, and treatment. These words signify a focus between providing services to those living with autism and seeking to find a cure for autism. As John Elder Robison (2013) writes, "to many neurodiversity proponents, talk of "cure" feels like an attack on their very being. They detest those words for the same reason other groups detest talk of "curing gayness" or "passing for white," and they perceive the accommodation of neurological differences as a similarly charged civil rights issue. If their diversity is part of their makeup they believe it's their right to be accepted and supported "as-is." They should not be made into something else - especially against their will - to fit some imagined societal ideal."

\section{Gaps}

During the process of constructing our taxonomy, we identified three gaps in the taxonomy where concepts were not fully represented. The presence of a gap in taxonomy can be a pointer to where an aspect of a concept has yet to be fully realized or to where voices of a group are not being surfaced in the discourse. In examining the phenomenon of autism diagnosis (2.4.1), we found concrete terms for an official diagnosis (2.4.1.1) from a medical professional, self-diagnosis (2.4.1.2), and community-diagnosis (2.4.1.3). However, we did not find a term for those who are in a middle state and are questioning whether they are autistic. Therefore, we proposed the term Neuro-Curious $(2.4 .1 .5)$ to represent the questioning, exploratory state 
Annuska Zolyomi and Joseph T. Tennis. 2017. Autism Prism: A domain Analysis Paper Examining Neurodiversity. NASKO, Vol. 6. pp. 139-172.

of someone who is exploring their neurodiversity, which may be autism or another neurodiverse condition. This term contrasts with someone suspected of being neurodiverse since suspected is from the perspective of a third-party person contemplating another person's neurodiversity.

In Medical and Care Strategies (2.5), we proposed Circle of Care (2.5.7) to acknowledge the group of people involved in a person's life beyond the interdisciplinary health team. People in a circle of care can include family members beyond the immediate family, community mentors, and close peers. Although the term ally (2.4.4.2) might be an appropriate term for some of these people, ally carries with it a connotation of advocacy which may not be an appropriate characterization. Also, we chose to highlight the care-taker or supporter role that people take since "some parents still feel excluded or not listened to by professionals across services. What is required is action to ensure that every parent and carer has a positive experience, especially when there are disagreements about what should happen" (Jones 2016, p.26).

The final gap was in Neurodiverse Conditions Other than Autism (3.0). There is not a definitive list of neurodiverse conditions since neurodiversity is claimed by a community or an individual, not determined by a medical classification. Therefore, we created other conditions due to neurological differences (3.5) to be inclusive of people who chose to identify with the neurodiversity movement.

\section{Identity}

Disability studies is a leading field surfacing perspectives on the nature and construction of identity and disability (S. Linton 1998; Davis 2017). Our domain analysis demonstrates ways that classification decisions impact an individual's sense of identity on individual and social levels. Their sense of self is conveyed by the terminology they chose to use, the groups they chose to associate with, and the way they describe their condition. Some people embrace the terminology closely tied to a diagnosis, such as autistic. Other people prefer, or also use, neurodiverse terms. Nomenclature is internalized by individuals and family who use terms of affection such as Auties (2.4.3.3) and Aspies (2.4.3.4). Then, when classifications strip away a term as Asperger was from the DSM, they struggle with the meaning of their Asperger diagnosis and identity (Giles 2014).

By capturing the terms related to diagnosis, we see that there are many paths to an individual's self-awareness of, and identification with, autism. Someone may be associating with others in the autism community, and then have someone suggest to them that they may be on the spectrum. There can be a period where an individual is neuro-curious (2.4.1.5) and is considering this information and what they would like to do to explore it further. They may or may not chose to pursue an official diagnosis. This implies that within the broad neurodiverse community, there are people at different stages of being out. As noted by Linton (1998), "disabled people also speak of "coming out" in the same way that members of the lesbian and gay community do" (p.21). It should also be noted that a person's identity may change over time and across groups. 
Annuska Zolyomi and Joseph T. Tennis. 2017. Autism Prism: A domain Analysis Paper Examining Neurodiversity. NASKO, Vol. 6. pp. 139-172.

\section{Implications to the Design of Information Systems}

This neurodiversity taxonomy is emergent and will change as the discourse continues to evolve. Information systems that build upon domain analysis use the taxonomy structure and definitions in their architecture and their user interface. A primary question is how can information systems be designed to support flexibility and changes over time? An overarching issue is that a taxonomy informs the information system designer's conceptualization of the user and the user's technology needs. The designer needs to have a grounded knowledge of the system audience. What information is important to them and what are their goals for using the system? What terms will they use to search or locate content? What sensitivities should the system embody to best reflect the intended audience's point of view? Perhaps there can be a notion of stability in a taxonomy to indicate nodes in which terms more likely to remain stable (e.g., autism), whereas other terms likely to evolve (e.g., low-functioning autism).

We should also consider how to build systems that adapt to changes to individuals' or groups' identities. Our taxonomy points to situations where identities may be in flux as an individual negotiates different social contexts. These various stages, and disclosure status, have implications for design of technology (and outreach programs) for the autism community. The design of technology should be cognizant of the potential stages of identity and disclosure to respect different levels of privacy and openness. Some information systems will have multiple end-users, such as an online forum about autism that is used by autistic people and their family. An educational system would have teachers, parents, and learners as end-users. Technology aims to meet the needs of multiple stakeholders, and therefore, a technology solution may need to adapt to different perspectives and terminology choices. The technology solution may even be able to help facilitate dialog and information sharing across medical and social models. For instance, technology programs could help disambiguate confusing terminology and facilitate dialog about differing points of view.

\section{Conclusion}

The neurodiversity taxonomy will continue to evolve as the as the community grows and evolves. Medical advances will also impact the taxonomy by introducing new terminology into the public discourse. There may be future modifications to the DSM as diagnostic needs change. As groups hold power in this dialog about autism, bias appears as one takes one a single point perspective. This domain analysis highlights that, despite the best of intentions, taxonomies describing human nature are prone to be embedded with bias. A path forward is to forefront the voices of the individuals in the community and to work together to create and integrate knowledge from domains such as medicine, social science, and information systems.

\section{Acknowledgements}

The authors thank Sally Stuart, PhD, LICSW, for sharing her knowledge about interdisciplinary health teams and development disabilities. We also thank Joanne Woiack for her insights on Disability Studies. 
Annuska Zolyomi and Joseph T. Tennis. 2017. Autism Prism: A domain Analysis Paper Examining Neurodiversity. NASKO, Vol. 6. pp. 139-172.

\section{Appendix: Neurodiversity Thesaurus}

0 . 0 Neurodiversity: "The whole of human mental or psychological neurological structures or behaviors, seen as not necessarily problematic, but as alternate, acceptable forms of human biology." ("Double-Tongued Dictionary Index | A Way with Words" 2016). "Differently brained" (Armstrong 2011).

1.0 People, in relationship to neurodiversity

1.1 Neurodiverse: "A group of people is neurodiverse if one or more members of the group differ substantially from other members, in terms of their neurocognitive functioning." (Walker 2014)

1.2 Neurodivergent: "Having a brain that functions in ways that diverge significantly from the dominant societal standards of "normal." (Walker 2014)

1.3 Multiple neurodivergent: Intersectionality of neurodiversity with more than one neurodiverse conditions

1.4 Neuro-atypical: Equivalent to 1.2 neurodivergent.

1.5 Neurotypical: "Having a style of neurocognitive functioning that falls within the dominant societal standards of "normal." Neurotypical is not synonymous with non-autistic. Neurotypical is the opposite of neurodivergent, not the opposite of autistic. Autism is only one of many forms of neurodivergence, so there are many, many people who are neither neurotypical nor autistic." (Walker 2014)

1.6 Predominant neurotype: Equivalent to 1.5 neurotypical (Beardon 2016).

1.7 Neurominority: Population of neurodivergent people whose neurodivergence, (1) "largely innate and that is inseparable from who they are, constituting an intrinsic and pervasive factor in their psyches, personalities, and fundamental ways of relating to the world, and (2) one to which the neurotypical majority tends to respond with some degree of prejudice, misunderstanding, discrimination, and/or oppression (often facilitated by classifying that form of neurodivergence as a medical pathology). Examples: autistic, bipolar, dyslexic, and schizophrenic people." (Walker 2014)

1.8 Neurodevelopmental disorders: "A group of conditions with onset in the developmental period. The disorders typically manifest early in development, often before the child enters grade school, and are characterized by developmental deficits that produce impairments of personal, social, academic, or occupational functioning.” (American Psychiatric Association 2013)

2.0 Autism Equivalent to 2.1.1 Autism Spectrum Disorder.

\subsection{Alternative and Narrower Terms}


Annuska Zolyomi and Joseph T. Tennis. 2017. Autism Prism: A domain Analysis Paper Examining Neurodiversity. NASKO, Vol. 6. pp. 139-172.

Alternative Terms:

2.1.1 Autism Spectrum Disorder (ASD): The official DSM-5 diagnosis, 299.00. Equivalent to 2.1. Autism with an emphasis that symptoms manifest in varying levels among different people. This definition below is a partial description the ASD diagnostic criteria, but is not the full criteria. Refer to the DSM-V for the full description, including considerations for severity, intellectual impairment, language impairment, genetic conditions, and other considerations.

"A. Persistent deficits in social communication and social interaction across multiple contexts, as manifested by the following: currently or by history (examples are illustrative, not exhaustive; see text):

1. Deficits in social-emotional reciprocity, ranging, for example, from abnormal social approach and failure of normal back-and-forth conversation; to reduced sharing of interests, emotions, or affect; to failure to initiate or respond to social interactions.

2. Deficits in nonverbal communicative behaviors used for social interaction, ranging, for example, from poorly integrated verbal and nonverbal communication; to abnormalities in eye contact and body language or deficits in understanding and use of gestures; to a total lack of facial expressions and nonverbal communication.

3. Deficits in developing, maintaining, and understand relationships, ranging, for example, from difficulties adjusting behavior to suit various social contexts; to difficulties in sharing imaginative play or in making friends; to absence of interest in peers.

B. Restricted, repetitive patterns of behavior, interests, or activities, as manifested by at least two of the following, currently or by history (examples are illustrative, not exhaustive; see text):

1. Stereotyped or repetitive motor movements, use of objects, or speech (e.g., simple motor stereotypes, lining up toys or flipping objects, echolalia, idiosyncratic phrases).

2. Insistence on sameness, inflexible adherence to routines, or ritualized patterns of verbal or nonverbal behavior (e.g., extreme distress at small changes, difficulties with transitions, rigid thinking patterns, greeting rituals, need to take same route or eat same food every day).

3. Highly restricted, fixated interests that are abnormal in intensity or focus (e.g., strong attachment to or preoccupation with unusual objects, excessively circumscribed or perseverative interests).

4. Hyper- or hypo- reactivity to sensory input or unusual interest in sensory aspects of the environment (e.g. apparent indifference to pain/temperature, adverse response to specific sounds or textures, excessive smelling or touching of objects, visual fascination with lights or movement). 
Annuska Zolyomi and Joseph T. Tennis. 2017. Autism Prism: A domain Analysis Paper Examining Neurodiversity. NASKO, Vol. 6. pp. 139-172.

C. Symptoms must be present in the early developmental period (but may not become fully manifest until social demands exceed limited capacities, or may be masked by learned strategies in later life).

D. Symptoms cause clinically significant impairment in social, occupational, or other important areas of current functioning.

E. These disturbances are not better explained by intellectual disability (intellectual developmental disorder) or global developmental delay. Intellectual disability and autism spectrum disorder frequently co-occur; to make comorbid diagnoses of autism spectrum disorder and intellectual disability, social communication should be below that expected for general developmental level." (American Psychiatric Association 2013; "DSM-5 Diagnostic Criteria" 2013)

2.1.1.1 ASD Severity Levels: Assigned as a component of the DSMV ASD diagnosis. Level 3: Requiring very substantial support. Level 2: Requiring substantial support. Level 1: Requiring support. (American Psychiatric Association 2013).

2.1.2 Autism Spectrum Condition: (ASC) Equivalent to 2.1.1 Autism Spectrum Disorder with a preference the more inclusive term, "condition." ASC may be considered by some as a psychological definition, whereas ASD may be considered as a medical diagnosis of ASD. "The autism spectrum could be experienced by individuals in one of two ways: as a different learning style that, when accommodated, could be thought of as ASC and part of difference and neural diversity; or, if this learning style is not accommodated and catered for, the individual's condition could develop into what could be thought of as ASD" (Lawson 2008, p.62).

Narrower Terms:

2.1.3 Autistic Disorder: DSM-IV 299.00 diagnosis that was superseded in DSMV with 2.1.1 Autism Spectrum Disorder. Historic term. Broader term 2.1.1 Autism Spectrum Disorder. Classified in ICD-10 as F84.0 Childhood Autism (Autism Aspergers Advocacy Australia 2017).

2.1.4 Asperger's Disorder: DSM-IV diagnosis that was superseded in DSM-V with 2.1.1 Autism Spectrum Disorder. Classified in ICD-10 as F84.5 Asperger Syndrome (Autism Aspergers Advocacy Australia 2017). This definition below is a partial description the ASD diagnostic criteria, but is not the full criteria. Refer to the DSM-V for the full description.

“A. Qualitative impairment in social interaction, as manifested by at least two of the following: 
Annuska Zolyomi and Joseph T. Tennis. 2017. Autism Prism: A domain Analysis Paper Examining Neurodiversity. NASKO, Vol. 6. pp. 139-172.

1. marked impairment in the use of multiple nonverbal behaviors, such as eye-toeye gaze, facial expression, body postures, and gestures to regulate social interaction

2. failure to develop peer relationships appropriate to developmental level

3. a lack of spontaneous seeking to share enjoyment, interests, or achievements with other people (e.g., by a lack of showing, bringing, or pointing out objects of interest to other people)

4. lack of social or emotional reciprocity

B. Restricted, repetitive, and stereotyped patterns of behavior, interests, and activities, as manifested by at least one of the following:

1. encompassing preoccupation with one or more stereotyped and restricted patterns of interest that is abnormal either in intensity or focus

2. apparently inflexible adherence to specific, nonfunctional routines or rituals

3. stereotyped and repetitive motor mannerisms (e.g., hand or finger flapping or twisting, or complex whole-body movements)

4. persistent preoccupation with parts of objects."

(American Psychiatric Association 2000; Interactive Autism Network 2017)

2.1.5 High Functioning Autism (HFA): Equivalent term 2.1.4 Asperger's Disorder, although there may be a distinction due to language. An individual who did not have a language delay meets the Asperger criteria. An individual who did have a language delay have HFA (Baron-Cohen et al. 2005). Broader term 2.1.1 Autism Spectrum Disorder.

2.1.6 Low Functioning Autism (LFA) Equivalent term 2.1.3 Autistic Disorder.

2.1.7 Classic Autism Equivalent term 2.1.3 Autistic Disorder.

2.1.8 Pervasive Developmental Disorder - Not Otherwise Specified (PDD-NOS) DSM-IV 299.80 diagnosis that was superseded in DSM-V with 2.1.1 Autism Spectrum Disorder. Historic term. Broader term 2.1.1 Autism Spectrum Disorder. ICD-10 classifications that map to DSM-IV PDD: F84.1 Atypical Autism, F84.8 Other pervasive developmental disorders, F84.9 Pervasive developmental disorders, unspecified (Autism Aspergers Advocacy Australia 2017).

\subsection{Related Conditions}

2.2.1 Attention Deficit / Hyperactivity Disorder (ADHD): “A persistent pattern of inattention and/or hyperactivity-impulsivity that interferes with functioning or development." Symptoms are present prior to age 12 years and are present in two or more settings. (American Psychiatric Association 2013). Comorbid to 2.1.1 Autism Spectrum Disorder. 
Annuska Zolyomi and Joseph T. Tennis. 2017. Autism Prism: A domain Analysis Paper Examining Neurodiversity. NASKO, Vol. 6. pp. 139-172.

2.2.2 Sensory Processing Difficulties: Hyper or hypo-sensitivity to sensory input (sounds, smells, tactile, visual, olfactory). Although there is not an official DSM-V Sensory Processing Disorder diagnosis, it is a clinical label and a common theme in accounts by people in the autism community. (Deweerdt 2016; Lane et al. 2010; Davidson and Henderson 2010). Kanner described an "intrusion comes from loud noises and moving objects, which are therefore reacted to with horror. Tricycles, swings, elevators, vacuum cleaners, running water, gas burners, mechanical toys, egg beaters, even the wind could on occasions bring about a major panic" (Kanner 1943 p. 245). The "sensory realities of embodied autistic individuals" (Davidson 2010a). Co-morbid to 2.1.1 Autism Spectrum Disorder.

2.2.3 Anxiety disorder "Disorders that share features of excessive fear and anxiety and related behavioral disturbances." (American Psychiatric Association 2013). Comorbid to 2.1.1 Autism spectrum Disorder.

2.2.4 Rett Syndrome: Diagnosis is based on loss of acquired purposeful hand movements, loss of acquired language, gait abnormalities, and stereotypic hand movements. Prevalence is much higher in females than males. (Briggs 2014). "According to the major classification systems it is not possible to diagnose a comorbid autistic disorder in persons with Rett syndrome. However, this is a controversial issue, and given the level of functioning of persons with Rett syndrome, the autistic disorder is expected to be present in a comparable proportion as in people with the same level of functioning. (Wulffaert, Van Berckelaer-Onnes, and Scholte 2009 p. 567). Classified in ICD-10 as F84.2 Rett's Syndrome (Autism Aspergers Advocacy Australia 2017). Related term 2.1.3 Autistic Disorder.

2.2.5 Childhood Disintegrative Disorder: DSM-IV classification (not DSM-V) developmental disorder impacting areas of language, social interaction, and motor skills. (American Psychiatric Association 2000). Classified in ICD-10 as F84.3 (Autism Aspergers Advocacy Australia 2017). Related terms 2.1.3 Autistic Disorder and 2. 1.8 Pervasive Developmental Disorder.

2.2.6 Tourette Syndrome: DSM-V 307.23 (ICD-10 F95.2) Characterized by motor and vocal tics for at least a year beginning before 18 years of age. (American Psychiatric Association 2013). Co-morbid to 2.1.1 Autism Spectrum Disorder.

2.2.7Related Genetic Disorders: Autism has been connected to a range of genetic diseases, including but not limited to, fragile $\mathrm{X}$, tuberous sclerosis, and Angelman syndrome (Cohen et al. 2005).

\subsection{Characteristics of Autism}


Annuska Zolyomi and Joseph T. Tennis. 2017. Autism Prism: A domain Analysis Paper Examining Neurodiversity. NASKO, Vol. 6. pp. 139-172.

2.3.1 Social Interaction: Involves social and emotional reciprocity, understanding social situations and other people's thoughts and feelings, and developing peer relationships (Baron-Cohen et al. 2005).

2.3.1.1 Insistence on sameness: "A marked limitation in the variety of his spontaneous activities. The child's behavior is governed by an anxiously obsessive desire for the maintenance of sameness that nobody by the child himself may disrupt on rare occasions. Changes of routine, of furniture arrangement, of a pattern, of the order in which every day acts are carried out, can drive him to despair" (Kanner 1943 p.246).

2.3.1.2 Play: Kanner described play in relation to objects and people. The child "has a good relation to objects; he is interest in them, can play with them happily for hours. He can be very fond of them, or get angry at them if, for instance, he cannot fit them into a certain space (Kanner 1943 p.246). He describes a preference for parallel play with peers. Play skills are targeted by evidence-based practices such as social skills training, structured play group, pivotal response training, and video modeling (Wong et al. 2014).

2.3.2 Communication: Verbal and non-verbal communication.

2.3.2.1 Verbal Communication: Language acquisition and use, including expressive language, receptive language, initiating and sustaining a conversation with others, engaging in topics beyond those of interest to self. (Baron-Cohen et al. 2005; Mayes et al. 2009).

2.3.2.2 Non-Verbal Communication: Includes eye gaze, facial expression, body posture, reading cues of conversation partner (BaronCohen et al. 2005).

2.3.2.3 Echolalia: "Inappropriately mimics what others say, such as repeating instead of answering a question" (Mayes et al. 2009 p.1691).

2.3.3 Behaviors: Forms of non-verbal actions; self-regulation; stereotyped interests.

2.3.3.1 Repetitive and Restricted Behaviors: "Preoccupation with one or more stereotyped and restricted patterns of interest that is abnormal either in intensity or focus (Baron-Cohen et al. 2005 p.813). "A behavior is defined as stereotypy when it...involves repetition, rigidity, and invariance, as well as a tendency to be inappropriate in nature...The social environment may serve to negatively or positively reinforce stereotyped behaviors" (Cunningham and Schreibman 2008 p2;7).

2.3.3.1.1 Self-Regulation: An individual's capacity to attend to their state of arousal. A high arousal state can manifest as agitation or hyper-activity (Case-Smith, Weaver, and Fristad 2014). 
Annuska Zolyomi and Joseph T. Tennis. 2017. Autism Prism: A domain Analysis Paper Examining Neurodiversity. NASKO, Vol. 6. pp. 139-172.

2.3.3.1.2 Self-Stimulating: Behaviors that "can help reorder the environment in more manageable terms" (Davidson 2010b). Equivalent to 2.3.3.1.4 Stimming.

2.3.3.1.3 Stereotyped or Repetitive Motor Mannerisms: Repetitive movements, "e.g., hand or finger flapping or twisting, or complex whole-body movements" (Baron-Cohen et al. 2005 p.813). "Stereotypical yet 'inexplicable' autistic actions - such as rocking, hand-flapping or humming - are intended to provide a rhythm of sorts against which the world can be more easily accessed and made sensible" (Davidson 2010a). Broader term 2.3.3.1.2 SelfStimulating.

2.3.3.1.4 Stimming: Repeated verbal, motor, or object actions. Equivalent to 2.3.3.1.2 SelfStimulating.

2.3.3.1.5 Tics: Mild to severe spontaneous motor movements or vocal utterances. Related term: 3.3 Tourette's Syndrome.

2.3.3.2 Preoccupation with parts of objects: "Persistent preoccupation with parts of objects/systems" (Baron-Cohen et al. 2005 p.813).

2.3.3.3 Stereotyped | Restricted Interests: Focus on a limited range of interests. Hyper-focus on an area of interest can lead to great creativity in that area in some cases (Chown 2016, p. 62).

2.3.3.3.1 Deep | Special Interest Equivalent term 2.3.3.3 Stereotyped | Restricted Interests.

2.3.3.3.2 Perseveration: Umbrella term for "Narrow or unusual range of interest and play behaviors. Obsessive preoccupations or extreme fixation on things such as certain movies... unusual attachment to and holding or hoarding objects...Stereotyped and repetitive play...Upset with change...Stereotypes (unusual repetitive movements)" (Mayes et al. 2009 p.1690-1691).

2.3.4 Cognitive Styles: A cognitive psychology term that describes how individuals perceive themselves and others, as well as how they process information. Some prevailing cognitive autism theories are theory of mind, executive (dys)functioning, central coherence, and hyper-systemizing. (Chown 2016). 
Annuska Zolyomi and Joseph T. Tennis. 2017. Autism Prism: A domain Analysis Paper Examining Neurodiversity. NASKO, Vol. 6. pp. 139-172.

2.3.4.1 Exceptional skills: Autistic individuals may exhibit "special abilities that are significantly higher than other abilities." (Mayes et al. 2009 p.1692). Example areas include memory, vocabulary, mimicking movie characters, visual-mechanical skills, artistic or musical talent, well-developed gross motor skills. Individuals may be talented in recognizing patterns, focusing on an area of interest, and an eye for detail.

\subsection{Identity}

2.4.1 Diagnosis: "Determination of the nature of a diseased condition; identification of a disease by careful investigation of its symptoms and history; also, the opinion (formally stated) resulting from such investigation. ("Oxford English Dictionary Online" 2016).

2.4.1.1 Official diagnosis: "There is no definitive medical or genetic test that can confirm whether or not a child or adult has or has not got autism. Instead, the diagnosis is made on the basis of observing and assessing the behaviours and skills of an individual and taking a history of their development from birth to the present day. The accuracy of the diagnosis therefore depends on the expertise and the experience of the team or person making the assessment" (Jones 2016 p.18). Two standardized autism assessment instruments are the Autism Diagnostic Interview-Revised and the Autism Diagnostic Observation Schedule (Volkmar et al. 2004). Related term 2.5.7 Interdisciplinary health team.

2.4.1.2 Self diagnosed: An individual who identifies with an autistic identity without an official diagnosis (Davidson and Orsini 2013).

2.4.1.3 Community diagnosed: An individual who arrives at identifying as a neurodiverse individual through their interactions with an online and/or off-line neurodiversity community (Davidson and Orsini 2013).

2.4.1.4 Suspected diagnosis: An individual who has not pursued or acquired an official autism diagnosis (Davidson and Orsini 2013).

2.4.1.5 Neuro-Curious: An individual is exploring their neurodiversity identity.

2.4.1.6 Undiagnosed: "The ratio of diagnosed to undiagnosed individuals is currently much greater in adulthood than in childhood, given that in the past far less was known about autism and specialist assessment services did not exist in many areas" (Jones 2016 p.18).

2.4.1.7 Misdiagnosed: An autistic individual receives a diagnosis of another condition (or autism has been incorrectly ruled out) prior to receiving a diagnosis of autism. (Jones 2016). 
Annuska Zolyomi and Joseph T. Tennis. 2017. Autism Prism: A domain Analysis Paper Examining Neurodiversity. NASKO, Vol. 6. pp. 139-172.

2.4.2 Disclosure: "The action or fact of disclosing or revealing new or secret information; the action of making something openly known ("Oxford English Dictionary Online" 2016).

2.4.2.1 Disclosed: An autism condition is revealed or made known.

2.4.2.2 Undisclosed: An autism condition is not revealed or made open.

2.4.2.3 Out: An autistic individual openly shares information about their autism.

2.4.2.4 Hidden | Invisible disability: An individual's disability is not apparent. "I don't look autistic or my needs are not as important as other people on the spectrum. Just because you cannot see it so therefore it's not there" (Kenny et al. 2015).

2.4.3 Nomenclature: "A name, a designation" ("Oxford English Dictionary Online" 2016).

2.4.3.1 Autistic: Identity-first language. "I am not a "person with autism." I am an autistic person... Saying "person with autism" suggests that the autism can be separated from the person. But this is not the case... Saying "person with autism" suggests that even if autism is part of the person, it isn't a very important part...Saying "person with autism" suggests that autism is something bad-so bad that it isn't even consistent with being a person. Nobody objects to using adjectives to refer to characteristics of a person that are considered positive or neutral." (Sinclair 2013)

2.4.3.2 Person with Autism: "The philosophy of using person first language demonstrates respect for people with disabilities by referring to them first as individuals, and then referring to their disability when it is needed (Blaska 1993 p.27).

2.4.3.3 Auties: People on the autism spectrum ("Auties.org" 2017)

2.4.3.4 Aspies: A strong identity originally formed around the DSM-IV Asperger's Disorder. (Giles 2014).

2.4.3.5 Neurodiverse: Refers to 1.0 Neuro-typical | Neurodiverse as an identity.

2.4.4 Social Justice: "Justice at the level of a society or state as regards the possession of wealth, commodities, opportunities, and privileges" ("Oxford English Dictionary Online" 2016).

2.4.4.1 Self-Advocate: An autism advocate who is on the autism spectrum. "The role and purpose of these self-advocacy organisations varies across cultural contexts, and we should be clear that the continuum of advocacy varies from loosely organised self-advocates operating almost as individual actors to more formalised organisations such as the Autistic Self Advocacy Network in the United States" (O'Dell et al. 2016 p.168). 
Annuska Zolyomi and Joseph T. Tennis. 2017. Autism Prism: A domain Analysis Paper Examining Neurodiversity. NASKO, Vol. 6. pp. 139-172.

2.4.4.2 Ally: An autism advocate or supporter who is not on the autism spectrum.

2.4.4.3 Autism Movement: Advocacy for the rights of autistic people demanding acceptance. There are opposing philosophies and agendas of advocacy organizations and advocates. On one end are advocates arguing for acceptance and a celebration of different ways of being. Mobilized efforts target areas such as autism-friendly and adapted workplaces. On the other end are advocates pushing for scientific research to advance autism treatments and to find a cure for autism. Related terms 2.4.4.4 Neurodiversity Paradigm and 2.5 .3 Cure.

2.4.4.4 Accommodations: "Under the Americans with Disabilities Act, covered employers are required to provide "reasonable accommodations" to qualified job applicants and employees with disabilities. In the employment context, a reasonable accommodation is defined as any change or adjustment to a job, the work environment, or the way things usually are done that would allow an individual with a disability to apply for a job, perform job functions, or enjoy equal access to benefits available to other individuals in the workplace" (U.S. Department of Labor 2017).

2.4.4.5 Neurodiversity Paradigm: "A perspective that recognizes neurodiversity as a naturally-occurring form of human diversity, like cultural diversity, racial diversity, gender diversity, diversity of physical ability, and diversity of sexual orientation" (Walker 2017).

2.4.4.6 Inclusivity: "The practice or policy of not excluding any person on the grounds of race, gender, religion, age, disability, etc." ("Oxford English Dictionary Online" 2016). "Inclusion means making available to each person with a disability the opportunity to experience all of the conditions of everyday living in the same way and place as individuals without disabilities (McLaughlin 2010 p.268).

2.4.4.7 Gender: Gender-related issues such as identity, sexuality, and diagnosis. There is a lower incidence of females diagnosed with autism, with recent studies suggesting a ratio of 4:1 males to females being diagnosed (Jones 2016). Research has pointed to gender-biased methodological issues (e.g., limited female sample sizes, ages targeted for diagnosis), diagnostic criteria, and assessment instruments (Rivet and Matson 2011). For example, the ASD criteria states that an autistic individual will exhibit limited reciprocity in social interactions, "Because girls and women are more likely to experience reciprocity, they may be less likely to receive an ASD diagnosis. A female participant expressed, "the new criteria is less sensitive to femalespecific behaviors” (K. F. Linton et al. 2014 p.74) 
Annuska Zolyomi and Joseph T. Tennis. 2017. Autism Prism: A domain Analysis Paper Examining Neurodiversity. NASKO, Vol. 6. pp. 139-172.

\subsection{Medical and Care Strategies}

2.5.1 Genetic Research: Scientific research that aims to identify "genetic variants that contribute to the risk of ASD...A central goal of genetic research in ASDs and other neuropsychiatric disorders is to nominate molecular pathways for further interrogation and thus to link biological mechanisms with behavior...The resulting knowledge should enable to discovery of new treatments (Robinson, Neale, and Hyman 2015 p.686-687).

2.5.2 Cause: "That which produces an effect; that which gives rise to any action, phenomenon, or condition" ("Oxford English Dictionary Online" 2016). Investigation and understanding of the etiology of autism.

2.5.3 Cure: Medical or remedial treatment ("Oxford English Dictionary Online" 2016). "Many individuals who embrace the concept of neurodiversity believe that people with differences do not need to be cured; they need help and accommodation instead." (Robison 2013)

2.5.4 Prevalence: "The condition of being widespread in a particular area or at a particular time; general occurrence, existence, practice, or acceptance; predominance, pervasiveness, frequency" ("Oxford English Dictionary Online" 2016). The current prevalence of ASD is 1 in 68 children (Center for Disease Control and Prevention 2017).

2.5.5 Treatment | Intervention: A specific, named approach or program put in place to receive goals and outcomes considered important to stakeholders (Jones 2016). "The evidence suggests that early intervention programs are indeed beneficial for children with autism, often improving developmental functioning and decreasing maladaptive behaviors and symptom severity at the level of group analysis (Rogers and Vismara 2008 p.1).

2.5.6 Therapy: "The medical treatment of disease; curative medical or psychiatric treatment" ("Oxford English Dictionary Online" 2016).

2.5.6.1 Speech Therapy: "The training of patients in the production of a full range of speech sounds" ("Oxford English Dictionary Online" 2016). In a 2005 research study, speech therapy was the most common intervention, "perhaps not surprising...given that communication impairment is a defining feature of autism" (Green et al. 2006 p.81).

2.5.6.2 Occupational Therapy: "The use of activities or equipment involved in daily living, work, and recreation to assist recovery from illness, injury, or disability and to improve independence and quality of life ("Oxford English Dictionary Online" 2016). Areas of focus for occupational therapists working with children and adolescents with autism include: "sensory processing, sensorimotor performance, socialbehavioral performance, self-care, participation in play...transition to 
Annuska Zolyomi and Joseph T. Tennis. 2017. Autism Prism: A domain Analysis Paper Examining Neurodiversity. NASKO, Vol. 6. pp. 139-172.

work, vocational skills, and independence in the community (CaseSmith and Arbesman 2008)

2.5.6.3 Physical Therapy: "The systematic use of exercises to promote physical fitness" ("Oxford English Dictionary Online" 2016). Assessment of an individual's musculoskeletal system, neuromuscular system, etc., and recommendations for a program to improve motor skills for daily activities (Subcommittee on Intervention for Children With Autism 2014).

2.5.6.4 Applied Behavior Analysis (ABA): "A behavioral science devoted to the experimental study of socially significant behavior as a function of environmental variables... Since the mid-80s the evidence suggesting that $\mathrm{ABA}$ intervention is beneficial to the intellectual, verbal, and social functioning of children with autism and autism spectrum disorders has accumulated steadily (Virués-Ortega 2010 p.387-388).

2.5.6.5 Social Skills Training: "Instruction on basic concepts, roleplaying or practice, and feedback to help learners acquire and practice communication, play, or social skills to promote positive interactions with peers (Wong et al. 2014 p.90).

2.5.7 Interdisciplinary health team: Integrated clinical services for an individual with autism and their families. May include pediatrician, social worker, Applied Behavior Analysis therapist, Physical/Occupational therapist, SpeechLanguage pathologist, and Audiologist. An interdisciplinary assessment model advocates for family-centered care, cultural competence, and a strengths perspective (Prelock et al. 2003).

2.5.8 Circle of Care: Collaborative partnerships between an autistic individual and trusted members of their community, which may include parents, peers, educators, community mentors, and medical practitioners.

2.5.9 Adaptive Behavior: Skills in domains of communication, independent living, self-help, social functioning, and motor. (Carter et al. 1998).

2.5.10 Non-traditional Strategies: Practices not supported by rigorous scientific research. Includes controversial and dangerous fads of facilitated communication, chelation therapy, and "the purported causal link between the MMR (mumps, measles, and rubella) vaccine and autism" (Jacobson, Foxx, and Mulick 2005 p.247). "Our understanding of autism and the development of effective treatments will not be advanced by the unequivocal dismissal of novel theories and innovative approaches...Science will not advance without new ideas. However, new treatment options should be conceptualized as experimental hypotheses and fully scrutinized through research. Interventions should emanate from a theoretical basis already rooted in what is known about the etiology and course of autism (Jacobson, Foxx, and Mulick 2005 p.257-258). 
Annuska Zolyomi and Joseph T. Tennis. 2017. Autism Prism: A domain Analysis Paper Examining Neurodiversity. NASKO, Vol. 6. pp. 139-172.

\section{6 Education Strategies}

2.6.1 Individualized Education Plan (IEP) : In the U.S., a K-12 student with a disability may receive services under an IEP or a 504 Plan (McLaughlin 2010). "The Education for Handicapped Children Act of 1975 mandates that public schools provide students with disabilities a "free appropriate public education" (FAPE) in the "least restrictive environment." The Act requires educators to develop an "individual education plan" (IEP) for each child receiving special education services...The Individuals with Disabilities Education Act (IDEA) of 1990 reauthorized The Education for Handicapped Children Act of 1975" (The Arc 2017; McLaughlin 2010). Related terms 2.6.2 Section 504 Plan; 2.6.3 Special Education.

2.6.2 Section 504 Plan: In the U.S., a K-12 student with a disability may receive services under an IEP or a 504 Plan (McLaughlin 2010). "In 1973, The Rehabilitation Act is rewritten providing stronger emphasis on people with severe disabilities. The Act requires vocational rehabilitation agencies to develop an "individualized written rehabilitation program" (IWRP) with each individual receiving services. Section 504 of the Act protects individuals with disabilities from discrimination in all federally assisted programs and activities." (The Arc 2017). Related term 2.6.1 Individualized Education Plan (IEP).

2.6.3 Special Education: Specially designed instruction designated by the U.S. Individuals with Disabilities Education Act (IDEA). Related term 2.6.1 Individualized Education Plan (IEP). The domain of education can be "defined as the fostering of acquisition of skills or knowledge-including not only academic learning, but also socialization, adaptive skills, language and communication, and reduction of behavior problems-to assist a child to develop independence and person responsibility" (National Research Council (U.S.) and Committee on Educational Interventions for Children with Autism 2001 p.12).

2.6.4 Mainstream: Used in the education domain for including learners with disabilities in general education settings. Mainstreaming aligns with the IDEA philosophy of servicing the learner in the Least Restrictive Environment. (National Research Council (U.S.) and Committee on Educational Interventions for Children with Autism 2001).

2.6.5 Evidence-Based Practices (EBPs) "Focused intervention practices that have evidence of effectiveness in promoting positive outcomes for learners with ASD” (Wong et al. 2014, p.3 ). The National Professional Development Center on ASD (NPDC), which was funded by the US Office of Special Education Programs in the US Department of Education, classified the following 27 interventions as EBPs: Antecedent-based intervention; Cognitive behavioral intervention; Differential reinforcement of Alternative, Incompatible, or Other Behavior; Discrete Trial Teaching; Exercise; Extinction; Functional behavior assessment; Functional communication training; Modeling; Naturalist intervention; Parent 
Annuska Zolyomi and Joseph T. Tennis. 2017. Autism Prism: A domain Analysis Paper Examining Neurodiversity. NASKO, Vol. 6. pp. 139-172.

implemented intervention; Peer-mediated instruction and intervention; Picture Exchange Communication System; Pivotal response training; Prompting; Reinforcement; Response interruption/redirection; Scripting; Self-management; Social narratives; Social skills training; Structured play groups; Task analysis; Technology-aided instruction and intervention; Time delay; Video modeling; and Visual support.

\subsection{Technology}

2.7.1 Assistive Technology (AT): Specialized hardware and software that provides alternative ways to access technology or to perform a technology-mediated activity. "AT is any commercial, hand-made, or customized device or service used to support or enhance the functional capabilities of individuals with disabilities. AT includes computer-assisted instruction, mobility devices, high and low technology adaptations and AAC" (National Research Council (U.S.) and Committee on Educational Interventions for Children with Autism 2001 p56-57).

2.7.1.1 Augmentative and Alternative Communication $(A A C)$ : Hardware devices and software applications that provide alternative modes of communication. "AAC may involve supporting existing speech or developing dependent use of a nonspeech symbol system, such as sign language, visual symbols (pictures and words) displayed on communication boards, and voice output devices with synthesized and digitized speech" (National Research Council (U.S.) and Committee on Educational Interventions for Children with Autism 2001 p56).

2.7.1.2 Technology-Aided Instruction and Intervention: In an education setting, practices in which a learner's goals or outcomes are supported primarily by technology. "Can be used effectively to address social, communication, behavior, joint attention, cognitive, school-readiness, academic, motor, adaptive, and vocational skills (Wong et al. 2014 p.96).

2.7.1.2.1 Speech Generating Devices: The evidencebased practice of using augmentative and alternative communication (Wong et al. 2014). Equivalent term 2.7.1.1 Augmentative and Alternative Communication.

2.7.1.2.2 Computer Aided Instruction: The evidencebased practice of using technology and instructional procedures used to meet specified goals or outcomes (Wong et al. 2014). 
Annuska Zolyomi and Joseph T. Tennis. 2017. Autism Prism: A domain Analysis Paper Examining Neurodiversity. NASKO, Vol. 6. pp. 139-172.

2.7.2 Accessible Technology: Mainstream and assistive technology that is accessible to people with disabilities and compatible with assistive technology.

2.7.3 Mainstream Technology: General-purpose software and hardware platforms and applications for purposes including education, work, socialization, communication, and personal pursuits. Individuals with autism use and adopt mainstream technology (Kientz et al. 2013).

\subsection{Non-Autism Neurodiverse Conditions}

3.1 Attention Deficit - Hyperactivity Disorder (ADHD) See 2.2.1 Attention-Deficit / Hyperactivity Disorder (ADHD) .

3.2 Learning Disabilities: Neurologically-based difficulty learning commonly affecting language (Dyslexia) and/or math (Dyscalculia).

3.3 Tourette Syndrome: See 2.2.6 Tourette Syndrome.

3.4 Obsessive Compulsive Disorder (OCD): The partial DSM-V definition of OCD (300.3) is: "Presence of obsessions, compulsions, or both. Obsessions are recurrent and persistent thoughts, urges, or impulses that the individual attempts to ignore or suppress...Compulsions are repetitive behaviors or mental acts ... aimed at preventing or reducing anxiety or distress (American Psychiatric Association 2013).

3.5 Other conditions due to neurological differences: May include those with traumatic brain injury, epilepsy, mental health and other conditions, depending on an individual's identity.

\section{References}

American Psychiatric Association. 2000. Diagnostic and Statistical Manual of Mental Disorders, Fourth Edition. DSM Library. American Psychiatric Association. doi:10.1176/appi.books.9780890420249.dsm-iv-tr.

—. 2013. Diagnostic and Statistical Manual of Mental Disorders, Fifth Edition. Arlington, VA: Author.

Anastasiou, D., and J. M. Kauffman. 2013. "The Social Model of Disability: Dichotomy between Impairment and Disability." Journal of Medicine and Philosophy 38 (4): 441-59. doi:10.1093/jmp/jht026.

Armstrong, Thomas. 2011. The Power of Neurodiversity: Unleashing the Advantages of Your Differently Wired Brain. Cambridge, MA: Da Capo Lifelong Books.

"Auties.org." 2017. Accessed May 14. http://www.auties.org/.

Autism Aspergers Advocacy Australia. 2017. "Autism Spectrum Disorder in DSMs and ICD-10.” Accessed May 13. http://www.a4.org.au/ASDformal.

“Autism Network International.” 2017. Accessed April 15. http://www.autismnetworkinternational.org/.

“Autism Speaks.” 2017. Accessed April 15. https://www.autismspeaks.org/. 
Annuska Zolyomi and Joseph T. Tennis. 2017. Autism Prism: A domain Analysis Paper Examining Neurodiversity. NASKO, Vol. 6. pp. 139-172.

“Autistic Self Advocacy Network | Nothing About Us Without Us.” 2017. Accessed April 15. http://autisticadvocacy.org/.

Baron-Cohen, Simon, Rosa A. Hoekstra, Rebecca Knickmeyer, and Sally Wheelwright. 2006. "The Autism-Spectrum Quotient (AQ) - Adolescent Version." Journal of Autism and Developmental Disorders 36 (3): 343-50. doi:10.1007/s10803-0060073-6.

Baron-Cohen, Simon, Sally Wheelwright, Janine Robinson, and Marc Woodbury-Smith. 2005. "The Adult Asperger Assessment (AAA): A Diagnostic Method." Journal of Autism and Developmental Disorders 35 (6): 807-19. doi:10.1007/s10803-0050026-5.

Beardon, Luke. 2016. "The Myths Of Autism.” Accessed December 23. http://autisticuk.org/the-myths-of-autism/.

Blaska, Joan. 1993. "The Power of Language: Speak and Write Using 'person First."” Perspectives on Disability, 25-32.

Briggs, Angela. 2014. "Primary Care of a Child with Rett Syndrome: Primary Care of a Child with Rett Syndrome." Journal of the American Association of Nurse Practitioners 26 (9): 471-80. doi:10.1002/2327-6924.12056.

Campbell, D. Grant. 2012. "Revisiting Farradane's Relational Indexing in a Consumer Health Context." In Facets of Knowledge Organization: Proceedings of the ISKO UK Second Biennial Conference, 4th-5th July, 2011, London, 25. Emerald Group Publishing.

http://books.google.com/books?hl=en\&lr=\&id=QdmYwK2BhjwC\&oi=fnd\&pg=P $\mathrm{A} 25 \& \mathrm{dq}=\% 22 \mathrm{emerged}+$ from $+\mathrm{a}+$ recognition+that+subject+access+is+both+a+se mantic+and+a+syntactic+challenge. $\% 22+\% 22$ also+have+consistent+and+useful+ ways+of+representing+how+those+concepts+combine $\% 22+\&$ ots=yef $1 \mathrm{Zk} 2 \mathrm{YcG} \&$ sig=L1SXrY1c5NoEXvjZPintbbWCTMs.

Carter, Alice S., Fred R. Volkmar, Sara S. Sparrow, Jing-Jen Wang, Catherine Lord, Geraldine Dawson, Eric Fombonne, Katherine Loveland, Gary Mesibov, and Eric Schopler. 1998. "The Vineland Adaptive Behavior Scales: Supplementary Norms for Individuals with Autism." Journal of Autism and Developmental Disorders 28 (4): 287-302.

Case-Smith, Jane, and Marian Arbesman. 2008. "Evidence-Based Review of Interventions for Autism Used in or of Relevance to Occupational Therapy." American Journal of Occupational Therapy 62 (4): 416-429.

Case-Smith, Jane, Lindy L. Weaver, and Mary A. Fristad. 2014. "A Systematic Review of Sensory Processing Interventions for Children with Autism Spectrum Disorders." Autism, 1362361313517762.

Center for Disease Control and Prevention. 2017. "Autism Spectrum Disorder - Data \& Statistics." CDC - Facts about Autism Spectrum Disorders - NCBDDD. Accessed May 14. http://www.cdc.gov/ncbddd/autism/facts.html.

Chown, Nick. 2016. Understanding and Evaluating Autism Theory. Jessica Kingsley Limited. http://www.jkp.com/uk/understanding-and-evaluating-autism-theory34484.html. 
Annuska Zolyomi and Joseph T. Tennis. 2017. Autism Prism: A domain Analysis Paper Examining Neurodiversity. NASKO, Vol. 6. pp. 139-172.

Cohen, David, Nadège Pichard, Sylvie Tordjman, Clarisse Baumann, Lydie Burglen, Elsa Excoffier, Gabriela Lazar, et al. 2005. "Specific Genetic Disorders and Autism: Clinical Contribution towards Their Identification." Journal of Autism and Developmental Disorders 35 (1): 103-16.

Cunningham, Allison B., and Laura Schreibman. 2008. "Stereotypy in Autism: The Importance of Function." Research in Autism Spectrum Disorders 2 (3): 469-79. doi:10.1016/j.rasd.2007.09.006.

Davidson, Joyce. 2010a. “'It Cuts Both Ways': A Relational Approach to Access and Accommodation for Autism." Social Science \& Medicine 70 (2): 305-12. doi:10.1016/j.socscimed.2009.10.017.

_ 2010b. "'It Cuts Both Ways': A Relational Approach to Access and Accommodation for Autism." Social Science \& Medicine 70 (2): 305-12. doi:10.1016/j.socscimed.2009.10.017.

Davidson, Joyce, and Victoria L. Henderson. 2010. “"Travel in Parallel with Us for a While': Sensory Geographies of Autism: 'Travel in Parallel with Us for a While."' Canadian Geographer / Le Géographe Canadien 54 (4): 462-75. doi:10.1111/j.1541-0064.2010.00309.x.

Davidson, Joyce, and Michael Orsini. 2013. Worlds of Autism: Across the Spectrum of Neurological Difference. University of Minnesota Press. https://www.upress.umn.edu/book-division/books/worlds-of-autism.

Davis, Lennard J. 2017. The Disability Studies Reader: 5th Edition. Routledge. https://www.routledge.com/The-Disability-Studies-Reader-5thEdition/Davis/p/book/9781138930230.

Deweerdt, Sarah. 2016. "Talking Sense: What Sensory Processing Disorder Says about Autism| Autism Research News." Spectrum | Autism Research News. June 1. https://spectrumnews.org/features/talking-sense-what-sensory-processingdisorder-says-about-autism/.

Donvan, John, and Caren Zucker. 2016. In a Different Key: The Story of Autism. New York: Crown.

“Double-Tongued Dictionary Index | A Way with Words.” 2016. Accessed December 24. https://www.waywordradio.org/dictionary-listing/.

“DSM-5 Diagnostic Criteria.” 2013. Autism Speaks. July 29. https://www.autismspeaks.org/what-autism/diagnosis/dsm-5-diagnostic-criteria.

Fox, Melodie J. 2016. "Legal Discourse's Epistemic Interplay with Sex and Gender Classification in the Dewey Decimal Classification System." Library Trends 64 (4): 687-713. doi:10.1353/lib.2016.0016.

Giles, David C. 2014. “'DSM-V Is Taking Away Our Identity’: The Reaction of the Online Community to the Proposed Changes in the Diagnosis of Asperger's Disorder." Health: 18 (2): 179-195.

Glidden, Derek, Walter Pierre Bouman, Bethany A. Jones, and Jon Arcelus. 2016. "Gender Dysphoria and Autism Spectrum Disorder: A Systematic Review of the Literature." Sexual Medicine Reviews 4 (1): 3-14. doi:10.1016/j.sxmr.2015.10.003. 
Annuska Zolyomi and Joseph T. Tennis. 2017. Autism Prism: A domain Analysis Paper Examining Neurodiversity. NASKO, Vol. 6. pp. 139-172.

Grandin, Temple, and Richard Panek. 2014. The Autistic Brain: Helping Different Kinds of Minds Succeed. Reprint edition. Mariner Books.

Green, Vanessa A., Keenan A. Pituch, Jonathan Itchon, Aram Choi, Mark O'Reilly, and Jeff Sigafoos. 2006. "Internet Survey of Treatments Used by Parents of Children with Autism." Research in Developmental Disabilities 27 (1): 70-84. doi:10.1016/j.ridd.2004.12.002.

Hjørland, Birger. 1998. "The Classification of Psychology: A Case Study in the Classification of a Knowledge Field." Knowledge Organization 25 (4): 162-201.

Interactive Autism Network. 2017. "DSM IV Criteria for Asperger's Disorder." Accessed May 10.

https://iancommunity.org/cs/about_asds/about_asds_dsm_iv_criteria_for_asperger s_syndrome.

Jacobson, John W., Richard M. Foxx, and James A. Mulick. 2005. Controversial Therapies for Developmental Disabilities: Fad, Fashion, and Science in Professional Practice. Routledge.

Jones, Glenys. 2016. "Missing and Misdiagnosis on the Autism Spectrum: Potential Consequences and Implications for Practice." Social Work \& Social Sciences Review 18 (1). http://search.ebscohost.com/login.aspx?direct=true\&profile=ehost\&scope=site\&au thtype $=$ crawler $\&$ jrnl $=09535225 \& A N=113212704 \& \mathrm{~h}=\mathrm{d} 9 \mathrm{a} 9 \mathrm{Hx} \% 2 \mathrm{~F} 8$ fiz1ZOrVW5 z2B\%2Bn11lEA68RZ022wOXklHuBIC5R162PcgRY7KEBg4tuooqXEZZ6VJld\% 2BkXzhBfy\%2F\%2Bw\%3D\%3D\&crl=c.

Kanner, Leo. 1943. "Autistic Disturbance of Affective Contact.” Nerv. Child 2: 217-50.

Kenny, Lorcan, Caroline Hattersley, Bonnie Molins, Carole Buckley, Carol Povey, and Elizabeth Pellicano. 2015. "Which Terms Should Be Used to Describe Autism? Perspectives from the UK Autism Community." Autism, 1362361315588200.

Kientz, Julie A., Matthew S. Goodwin, Gillian R. Hayes, and Gregory D. Abowd. 2013. "Interactive Technologies for Autism." Synthesis Lectures on Assistive, Rehabilitative, and Health-Preserving Technologies 2 (2): 1-177. doi:10.2200/S00533ED1V01Y201309ARH004.

Kwasnik, Barbara, and Mary Grace Flaherty. 2010. "Harmonizing Professional and NonProfessional Classifications for Enhanced Knowledge Representation." In Advances in Knowledge Organization, 12:229-35. International Society for Knowledge Organization. https://experts.syr.edu/en/publications/harmonizingprofessional-and-non-professional-classifications-for.

Lane, Alison E., Robyn L. Young, Amy E. Z. Baker, and Manya T. Angley. 2010. "Sensory Processing Subtypes in Autism: Association with Adaptive Behavior." Journal of Autism and Developmental Disorders 40 (1): 112-22. doi:10.1007/s10803-0090840-2.

Lawson, Wendy. 2008. Concepts of Normality. Jessica Kingsley Publishers. http://ebookcentral.proquest.com.offcampus.lib.washington.edu/lib/washington/de tail.action?docID=366690.

Linton, K. F., T. E. Krcek, L. M. Sensui, and J. L. H. Spillers. 2014. “Opinions of People 
Annuska Zolyomi and Joseph T. Tennis. 2017. Autism Prism: A domain Analysis Paper Examining Neurodiversity. NASKO, Vol. 6. pp. 139-172.

Who Self-Identify With Autism and Asperger's on DSM-5 Criteria." Research on Social Work Practice 24 (1): 67-77. doi:10.1177/1049731513495457.

Linton, Simi. 1998. Claiming Disability. http://nyupress.org/books/9780814751343/.

Mannion, Arlene, and Geraldine Leader. 2013. "Comorbidity in Autism Spectrum

Disorder: A Literature Review.” Research in Autism Spectrum Disorders 7 (12):

1595-1616. doi:10.1016/j.rasd.2013.09.006.

Mayes, Susan Dickerson, Susan L. Calhoun, Michael J. Murray, Jill D. Morrow, Kirsten K. L. Yurich, Fauzia Mahr, Shiyoko Cothren, Heather Purichia, James N. Bouder, and Christopher Petersen. 2009. "Comparison of Scores on the Checklist for Autism Spectrum Disorder, Childhood Autism Rating Scale, and Gilliam Asperger's Disorder Scale for Children with Low Functioning Autism, High Functioning Autism, Asperger's Disorder, ADHD, and Typical Development." Journal of Autism and Developmental Disorders 39 (12): 1682-93. doi:10.1007/s10803-009-0812-6.

McLaughlin, Margaret J. 2010. "Evolving Interpretations of Educational Equity and Students with Disabilities." Exceptional Children 76 (3): 265-278.

National Research Council (U.S.), and Committee on Educational Interventions for Children with Autism. 2001. Educating Children with Autism. Washington, DC: National Academy Press. http://public.eblib.com/choice/publicfullrecord.aspx?p=3375258.

O’Dell, Lindsay, Hanna Bertilsdotter Rosqvist, Francisco Ortega, Charlotte Brownlow, and Michael Orsini. 2016. "Critical Autism Studies: Exploring Epistemic Dialogues and Intersections, Challenging Dominant Understandings of Autism." Disability \& Society 31 (2): 166-179.

Oliver, Mike. 1990. "The Individual and Social Models of Disability.” July 23. http://pf7d7vi404s1dxh27mla5569.wpengine.netdna-cdn.com/files/library/Oliverin-soc-dis.pdf.

Olson, Hope A. 2001. "The Power to Name: Representation in Library Catalogs." Signs 26 (3): 639-68.

“Oxford English Dictionary Online." 2016. Oxford University Press. http://www.oed.com/.

Prelock, Patricia A., Jean Beatson, Brooke Bitner, Carri Broder, and Amy Ducker. 2003. "Interdisciplinary Assessment of Young Children with Autism Spectrum Disorder." Language, Speech, and Hearing Services in Schools 34 (3): 194-202.

Rivet, Tessa Taylor, and Johnny L. Matson. 2011. "Gender Differences in Core Symptomatology in Autism Spectrum Disorders across the Lifespan." Journal of Developmental and Physical Disabilities 23 (5): 399-420. doi:10.1007/s10882011-9235-3.

Robinson, Elise B., Benjamin M. Neale, and Steven E. Hyman. 2015. "Genetic Research in Autism Spectrum Disorders:" Current Opinion in Pediatrics 27 (6): 685-91. doi:10.1097/MOP.0000000000000278.

Robison, John Elder. 2013. "What Is Neurodiversity?” Psychology Today, October 7. http://www.psychologytoday.com/blog/my-life-aspergers/201310/what-isneurodiversity. 
Annuska Zolyomi and Joseph T. Tennis. 2017. Autism Prism: A domain Analysis Paper Examining Neurodiversity. NASKO, Vol. 6. pp. 139-172.

Rogers, Sally J., and Laurie A. Vismara. 2008. "Evidence-Based Comprehensive Treatments for Early Autism." Journal of Clinical Child \& Adolescent Psychology 37 (1): 8-38. doi:10.1080/15374410701817808.

Silberman, Steve. 2016. "Neurotribes: The Legacy of Autism and the Future of Neurodiversity." Accessed February 16. http://stevesilberman.com/book/neurotribes/.

Sinclair, Jim. 2013. "Why I Dislike 'person First' Language.” Autonomy, the Critical Journal of Interdisciplinary Autism Studies 1 (2). http://www.larryarnold.net/Autonomy/index.php/autonomy/article/view/22.

Singer, Judy. 1999. “'Why Can't You Be Normal for Once in Your Life?' From a 'problem with No Name' to the Emergence of a New Category of Difference." Disability Discourse.

- 2016. NeuroDiversity: The Birth of an Idea. Kindle. Judy Singer.

"Spectrums Magazine from Autism Empowerment." 2017. Accessed April 15. http://spectrumsmagazine.com/.

Subcommittee on Intervention for Children With Autsim. 2014. "Practice Recommendations for the School-Based Physical Therapy Evaluation of Children With Autism Spectrum Disorder." American Physical Theray Association Section on Pediatrics School-Based Special-Interest Goup. https://pediatricapta.org/includes/factsheets/pdfs $/ 14 \% 20$ Prac $\% 20$ Rec $\% 20$ for $\% 20$ Schools $\% 20$ for $\% 20$ Eval $\% 20$ of $\% 20 \mathrm{Au}$ tism.pdf.

The Arc. 2017. "The Arc|Key Federal Laws." Accessed May 12. http://www.thearc.org/what-we-do/public-policy/know-your-rights/federal-laws.

"The National Autistic People's Organisation." 2017. Accessed April 15. https://autisticuk.org/.

U.S. Department of Labor. 2017. "Office of Disability Employment Policy Accommodations." Accessed May 15. https://www.dol.gov/odep/topics/Accommodations.htm.

Virués-Ortega, Javier. 2010. “Applied Behavior Analytic Intervention for Autism in Early Childhood: Meta-Analysis, Meta-Regression and Dose-response Meta-Analysis of Multiple Outcomes." Clinical Psychology Review 30 (4): 387-99. doi:10.1016/j.cpr.2010.01.008.

Volkmar, Fred R., Catherine Lord, Anthony Bailey, Robert T. Schultz, and Ami Klin. 2004. "Autism and Pervasive Developmental Disorders." Journal of Child Psychology and Psychiatry 45 (1): 135-170.

Volkmar, Fred R., and James C. McPartland. 2014. "From Kanner to DSM-5: Autism as an Evolving Diagnostic Concept." Annual Review of Clinical Psychology 10 (1): 193-212. doi:10.1146/annurev-clinpsy-032813-153710.

Walker, Nick. 2014. "Neurodiversity: Some Basic Terms \& Definitions." Neurocosmopolitanism. September 27. http://neurocosmopolitanism.com/neurodiversity-some-basic-terms-definitions/.

_ 2017. 'Neurocosmopolitanism: Nick Walker's Notes on Neurodiversity, Autism, 
Annuska Zolyomi and Joseph T. Tennis. 2017. Autism Prism: A domain Analysis Paper Examining Neurodiversity. NASKO, Vol. 6. pp. 139-172.

and Cognitive Liberty.” Accessed April 15. http://neurocosmopolitanism.com/. Wong, Connie, Samuel L. Odom, Kara Hume, Ann W. Cox, Angel Fettig, Suzanne Kucharczyk, Matthew E. Brock, Joshua B. Plavnick, Veronica P. Fleury, and Tia R. Schultz. 2014. "Evidence-Based Practices for Children, Youth, and Young Adults with Autism Spectrum Disorder." Chapel Hill: The University of North Carolina, Frank Porter Graham Child Development Institute, Autism EvidenceBased Practice Review Group.

http://autismpdc.fpg.unc.edu/sites/autismpdc.fpg.unc.edu/files/2014-EBPReport.pdf.

World Health Organization. 2010. "International Statistical Classification of Diseases and Related Health Problems (ICD-10), 10th Revision." http://apps.who.int/classifications/icd10/browse/2010/en\#/F80-F89.

Wulffaert, Josette, Ina A. Van Berckelaer-Onnes, and Evert M. Scholte. 2009. "Autistic Disorder Symptoms in Rett Syndrome." Autism 13 (6): 567-81. doi:10.1177/1362361309338184. 